\title{
Effect of capsaicin and cimetidine on the healing of acetic acid induced gastric ulceration in the rat
}

\author{
J Y Kang, C H Teng, F C Chen
}

\begin{abstract}
Background-Capsaicin protects the gastric mucosa against experimental injury while capsaicin desensitisation reduces the rate of gastric ulcer healing. The effect of exogenous capsaicin on gastric ulcer healing has not to date been reported.
\end{abstract}

Aim/method-To investigate the effect of capsaicin, cimetidine, and in combination, given intragastrically in the healing of acetic acid induced chronic gastric ulcer in the rat. Treatment started immediately after ulcer induction.

Results-At the end of one week, capsaicin, cimetidine, and in combination increased ulcer healing but the effect of combined treatment was less than that of capsaicin alone. In an in vivo gastric chamber preparation, capsaicin increased, while cimetidine decreased, gastric mucosal blood flow measured by laser Doppler flowmetry. A dose response effect in reduction of gastric mucosal blood flow could be demonstrated for cimetidine. The gastric hyperaemic effect of capsaicin was blunted by prior administration of cimetidine. In contrast, capsaicin had no effect on gastric acid secretion and its addition to cimetidine did not affect the acid suppressant effect of the latter.

Conclusions-Capsaicin promotes the healing of acetic acid induced gastric effect. Although cimetidine also promotes ulcer healing due to its inhibitory effect on acid secretion it may have an antagonistic effect on the gastric ulcer healing effect of capsaicin by virtue of inhibition of gastric hyperaemia.

(Gut 1996; 38: 832-836)

Keywords: capsaicin, cimetidine, acetic acid induced gastric ulcer, gastric ulcer healing, gastric mucosal blood flow, gastric acid secretion.

Gastroenterology,

Department of

Medicine

J Y Kang

C H Teng

and Department of Physiology

F C Chen

National University of Singapore Correspondence to: Dr J Y Kang, Divisic Gastroenterology, Department of Medicine, National University Hospita 5 Lower Kent Ridge Road, Singapore 0511.

Accepted for publication 19 January 1996

Capsaicin has a gastroprotective effect and reduces the amount of gastric mucosal injury produced by various necrotising agents such as ethanol and aspirin. ${ }^{1-3}$ Sensory ablation by capsaicin impairs recovery from gastric mucosal damage produced by hydrochloric acid ${ }^{4}$ and acetic acid induced ulceration, ${ }^{5}$ although the process of rapid restitution remains unaffected. ${ }^{6}$ The use of exogenous capsaicin in animals with intact innervation to promote the healing of experimental gastric ulcer has not, however, been studied to our knowledge. Suppressants of gastric acid secretion, in contrast, are known to ulcer, probably by its gastric hyperaemic

increase the healing of both human and experimental gastric ulcer. ${ }^{78}$ The aims of this study are, firstly, to determine the effect of capsaicin on the healing of acetic acid induced gastric ulceration in the rat, comparing this effect with that of cimetidine, an inhibitor of gastric acid secretion widely used in human peptic ulcer disease, and evaluating the effect of combined treatment, and secondly, to determine the effect of capsaicin, cimetidine, and combined treatment on gastric mucosal blood flow and gastric acid output as possible mechanisms by which ulcer healing may be promoted.

\section{Methods}

\section{GASTRIC ULCER HEALING}

\section{Animal preparation}

Male Sprague-Dawley rats weighing approximately $200 \mathrm{~g}$ were used for this study. They were acclimatised in the animal house for one week prior to the study. Chronic gastric ulcers were produced by direct application of acetic acid using a modification of the method previously described by $\mathrm{Okabe}^{9}$ and Konturek. ${ }^{10}$ General anaesthesia was induced by intraperitoneal administration of pentobarbitone $35 \mathrm{mg} / \mathrm{kg}$. Laparotomy was performed through a midline epigastric incision and the stomach exposed. A plastic mould of $10 \mathrm{~mm}$ diameter was applied tightly to the serosal surface of the anterior wall of the stomach just proximal to the antrum and $120 \mu \mathrm{l}$ glacial acetic acid was poured through the mould onto the surface of the stomach for 20 seconds. The procedure was then repeated for the posterior wall of the stomach. The abdomen was closed with catgut and silk. The body temperature of the animals was kept at $37^{\circ} \mathrm{C}$ and the animals were allowed to recover from the anaesthesia. They were then divided into four groups and given unlimited normal diet and water for the next seven days.

\section{Experimental protocol}

The animals were divided into four groups and treated daily by gavage with either $1 \mathrm{ml}$ of solvent, $5 \mathrm{mg}$ of capsaicin in $1 \mathrm{ml}$ of solvent, $40 \mathrm{mg}$ of cimetidine in $1 \mathrm{ml}$ of solvent, or $5 \mathrm{mg}$ of capsaicin plus $40 \mathrm{mg}$ of cimetidine in $1 \mathrm{ml}$ of solvent. At the end of one week, the animals were killed and their stomachs removed, opened along the greater curvature, fixed in $10 \%$ neutral buffered formalin overnight, and photographs taken. The area of the entire gastric mucosa and any ulcers that were present were measured with a digital planimeter by an 
observer who was unaware of which group each animal belonged to.

\section{GASTRIC BLOOD FLOW}

\section{Animal preparation}

We used the gastric chamber technique described by Mersereau. ${ }^{11}$ Male SpragueDawley rats weighing approximately $200 \mathrm{~g}$ were used. They were acclimatised in the animal house for one week prior to the study and deprived of food for 24 hours prior to the experiment but permitted free access to water. Each animal was anaesthetised with Clinical Research Centre (CRC) cocktail. This was given intraperitoneally at a dose of $0.3 \mathrm{ml} /$ $100 \mathrm{~g}$. The body temperature was maintained at $36 \pm 0.5^{\circ} \mathrm{C}$ using a homeothermic blanket (Harvard, Oldham, UK) throughout the experiment. Laparotomy was performed through a midline epigastric incision. The stomach was exposed and delivered into the abdominal surface by gentle traction. It was then drawn through the centre hole of a plastic platform placed over the animal, opened along the greater curvature, mucosal side uppermost, and the edges pinned out. A plastic rim was then applied and tightened down. An ex vivo gastric chamber was thus made with the major vasculature left intact. The glandular mucosa in the chamber was washed with three changes of normal saline $(0 \cdot 15 \mathrm{~N}$ sodium chloride) and bathed with another $1.5 \mathrm{ml}$ of normal saline.

\section{Blood flow measurement}

Gastric mucosal blood flow was measured by a laser Doppler flowmeter (Periflux 4001, Perimed, Sweden) and recorded by the Perisoft programme (Perimed, Sweden): the frequency was $12 \mathrm{KHz}$ and the time constant 1.5 second. The zero value was defined by placing the laser prove against a white board. The probe was placed just above the perpendicular to the mucosal surface and its position fixed by a metal stand. Measurements were made continuously and at the same site at the anterior wall of the glandular part of the stomach. The readings were transferred on to floppy disks for subsequent analysis. Areas

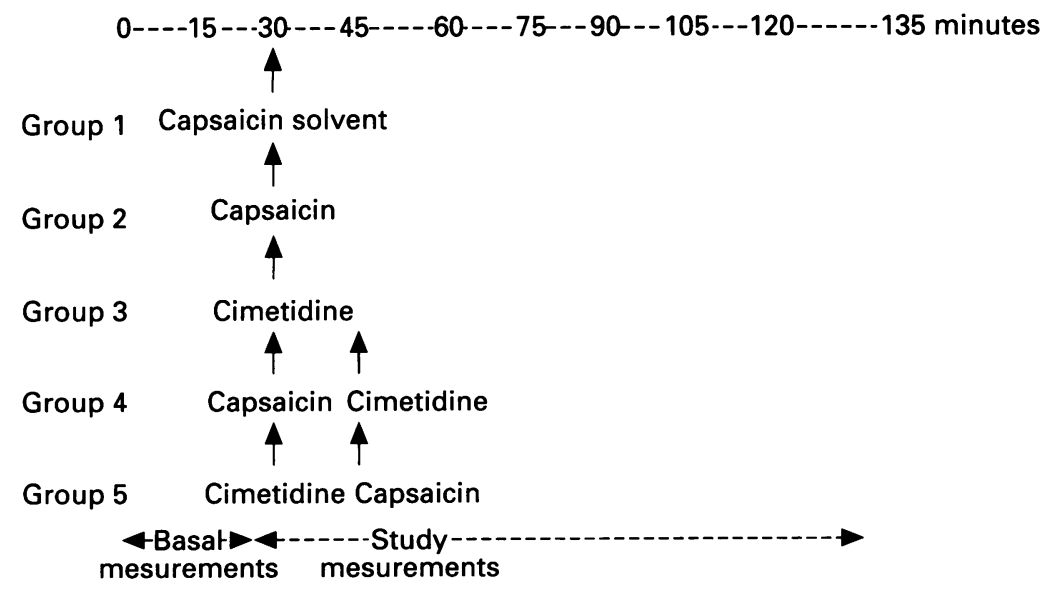

Figure 1: Sequence of administration of capsaicin/cimetidine/vehicle and measurement of gastric mucosal blood flow. under the curve were derived in arbitrary units for quantification of gastric mucosal blood flow over defined time periods.

\section{Experimental protocol}

Effect of capsaicin, cimetidine, and combined treatment (study A) - after a stabilising period of at least 30 minutes recording of blood flow was begun and continued for up to 135 minutes. Gastric contents were gently aspirated from the chamber every 15 minutes for $\mathrm{pH}$ analysis. Basal blood flow was recorded for 30 minutes. The animals were studied in five groups of eight. For each group one of the following was introduced into the chamber at the end of the basal period: (1) $2 \mathrm{ml}$ capsaicin solvent; (2) 5 mg of capsaicin in $2 \mathrm{ml}$ solvent; (3) $40 \mathrm{mg}$ of cimetidine suspended in $2 \mathrm{ml}$ capsaicin solvent; (4) $5 \mathrm{mg}$ of capsaicin in $2 \mathrm{ml}$ solvent followed 15 minutes later by $40 \mathrm{mg}$ of cimetidine suspended in $2 \mathrm{ml}$ solvent; (5) $40 \mathrm{mg}$ of cimetidine suspended in $2 \mathrm{ml}$ capsaicin solvent followed 15 minutes later by $5 \mathrm{mg}$ of capsaicin in $2 \mathrm{ml}$ solvent. Each solution was removed at the end of 15 minutes and replaced with normal saline. In the case of groups 4 and 5 , the first solution or suspension was introduced after 30 minutes of basal recording, removed after another 15 minutes, and the second solution or suspension introduced. Blood flow changes due to various test substances were studied after 45 minutes for groups 1-3 but after 30 minutes for groups 4 and 5 (Fig 1).

Dose response study for cimetidine (study B) the gastric mucosal blood flow study was repeated using four different doses of cimetidine (20 mg, $40 \mathrm{mg}, 80 \mathrm{mg}$, and $160 \mathrm{mg}$ ), as well as solvent and capsaicin as controls.

\section{MEASUREMENT OF GASTRIC ACID SECRETION}

Throughout the basal and test periods gastric juice was gently aspirated every 15 minutes and replaced with normal saline. Gastric acid secretion was measured by titrating the gastric juice to pH 7 with $0.05 \mathrm{~N} \mathrm{NaOH}$ using an auto-titrator (Radiometer $\mathrm{Co}$, Copenhagen, Denmark).

\section{REAGENTS}

Capsaicin, cimetidine, and TWEEN 80 reagents were purchased from Sigma Chemicals (St Louis, USA). Capsaicin and cimetidine were dissolved and suspended respectively in a solvent consisting of $10 \%$ ethanol, $10 \%$ TWEEN 80 , and $80 \%$ distilled water, volume for volume. CRC cocktail comprised a mixture of $1 \mathrm{ml}$ of Hypnorm (Janssens, Beerse) that contained $0.315 \mathrm{mg}$ of fentanyl and $10 \mathrm{mg}$ of fluanisone, plus $1 \mathrm{ml}$ of midazolam (Roche, Basel) that contained $5 \mathrm{mg}$ of dormicum, diluted to a $4 \mathrm{ml}$ volume with distilled water. For 100 grams of rat, $0.3 \mathrm{ml}$ of the cocktail was used, containing $0.024 \mathrm{mg}$ of fentanyl, $0.75 \mathrm{mg}$ fluanisone, and $0.38 \mathrm{mg}$ of midazolam. Pentobarbitone sodium was obtained as veterinary nembutal (Abbotts, Paris). 
STATISTICAL ANALYSIS

The first reading of gastric blood flow was taken as the basal blood flow. Subsequent readings of blood flow taken at 15 minute intervals were expressed as percentages of the basal blood flow. Areas under the curve were calculated for the 90 minute periods after exposure to the test substance, or the first test substance. For comparison of acid secretion in study A, the total amounts of gastric juice collected over the pre- and post-treatment periods were compared. For each group two 15 minute collections prior to treatment were considered, plus five 15 minute collections after treatment. For the control, capsaicin, cimetidine, and cimetidine plus capsaicin groups, the post-treatment collection began immediately after the introduction of the only or first test substance. For the capsaicin plus cimetidine group, however, only the five treatment periods after cimetidine were considered. The 15 minute period after capsaicin use but before cimetidine was given was not taken into account. For study B, two 15 minute collections made before treatment and six after were studied.

Statistical analysis was performed using the Statistical Package for Social Sciences for Windows (SPSSWIN). One way analysis of variance was performed to detect statistical differences between the groups. Where treatment of data requiring non-parametric techniques was needed, the variables were ranked and analyses performed on the ranked data. This was to avoid the use of the non-parametric Kruskal-Wallis test, which yields a $\chi^{2}$ statistic with one degree of freedom. Analysis of variance on ranked data gives a more rigorous test as it uses the $F$ test. ${ }^{12}$ Probability values less than 0.05 were considered significant.

\section{Results}

\section{GASTRIC ULCER HEALING}

Five of 45 animals who underwent induction of gastric ulcer did not recover from the anaesthetic. These 40 animals survived the one week of the experiment but in one rat dense adhesions around the stomach precluded satisfactory dissection and measurement of ulcer size. Overall, the animals grew from a mean body weight of $209.9 \mathrm{~g}$ to a mean weight of $234.1 \mathrm{~g}$. There was no difference in weight gain between the four groups of animals. Other workers have shown that the initial area of ulcers measured one day after acetic acid induction was similar to the size of the mould. ${ }^{13}$ The Table shows the degree of ulcer healing in the various groups. Both cimetidine and capsaicin were effective in reducing the ulcer size compared with capsaicin solvent. Combination treatment with both capsaicin and cimetidine likewise reduced ulcer size compared with the use of capsaicin solvent. However, ulcer size was numerically greater in the combined group compared with the use of either capsaicin or cimetidine alone. The difference between the combined group and the capsaicin group was statistically significant.
Gastric ulcer size in various treatment groups

\begin{tabular}{llll}
\hline Treatment & Number & $\begin{array}{l}\text { Number with } \\
\text { healed ulcer }\end{array}$ & $\begin{array}{l}\text { Ulcer size } \\
\left(\mathrm{mm}^{2}(\text { SEM)) }\right.\end{array}$ \\
\hline Control & 10 & 0 & $165(15)$ \\
Capsaicin & 10 & 1 & $57(20)^{\star}$ \\
Cimetidine & 9 & 0 & $82(32) \dagger$ \\
$\begin{array}{l}\text { Capsaicin plus } \\
\text { cimetidine }\end{array}$ & 10 & 1 & $106(18) \ddagger$ \\
\hline
\end{tabular}

${ }^{\star}+\neq \mathrm{p}<0.005$ versus control, ${ }^{\star} v \neq \mathrm{p}<0.05$.

Two animals had completely healed ulcers: one in the capsaicin group and one in the combined capsaicin and cimetidine group.

\section{GASTRIC BLOOD FLOW}

\section{Effect of capsaicin, cimetidine, and their combination}

The rate of blood flow remained steady for the control group throughout the 120 minute period of study. The use of capsaicin increased blood flow over control values (Fig 2). Exposure to cimetidine reduced blood flow rates from those of the control group (Fig 2). With combined treatment using both capsaicin and cimetidine the results were different depending on the order of administration (Fig 3). When capsaicin was given before cimetidine, there were still significant increases in blood flow over control values similar to the group given capsaicin alone. In contrast, when cimetidine was given before capsaicin, there was no significant increase in blood flow compared with control values even though flow rates were still significantly greater than in animals treated with cimetidine alone.

The areas under the curve for the solvent, capsaicin, cimetidine, capsaicin plus cimetidine, and cimetidine plus capsaicin groups were (mean (SEM) units): 579.6 (12.1), 752.6 $(32.3)(p<0.05$ versus control, cimetidine, and cimetidine plus capsaicin groups), 500.4 (20.7) $(p<0.05$ versus all the other four groups), 735.8 $(44.9)(p<0.05$ versus control, cimetidine, and cimetidine plus capsaicin group), and 620.8 $(26.9)(\mathrm{p}<0-\cdot 05$ versus capsaicin, capsaicin plus cimetidine, and cimetidine groups).

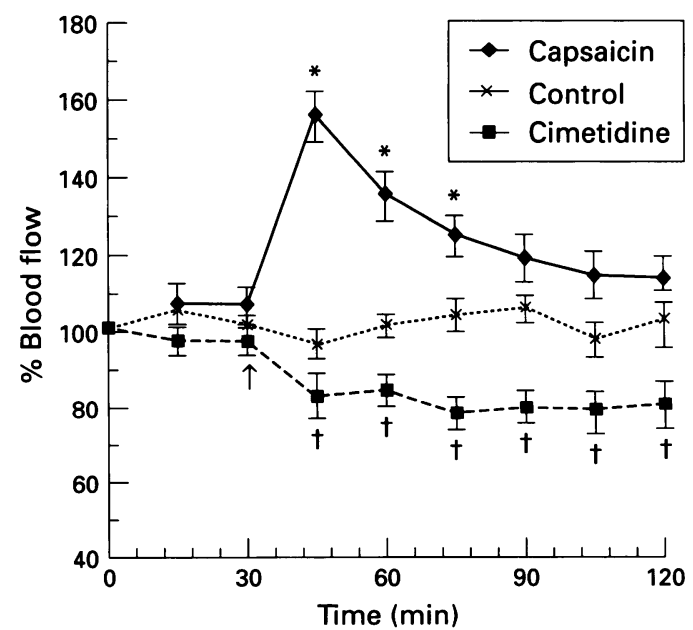

Figure 2: Effect of capsaicin and cimetidine on gastric mucosal blood flow ( $n=14$ per group). Data shown as mean (SEM). Time of exposure to drug arrowed. ${ }^{\star} p<0.05$ capsaicin $\mathrm{v}$ control; $\dagger p<0.05$ cimetidine $\mathrm{v}$ control. 
Figure 3: Effect of combined capsaicin and mucosal blood flow $(n=14$ per group). Data shown as mean (SEM). Time (s) of exposure to $\operatorname{drug}(s)$ arrowed. ${ }^{\star} p<0.05$ capsaicin +cimetidine $\mathrm{v}$ control. cimetidine on gastric

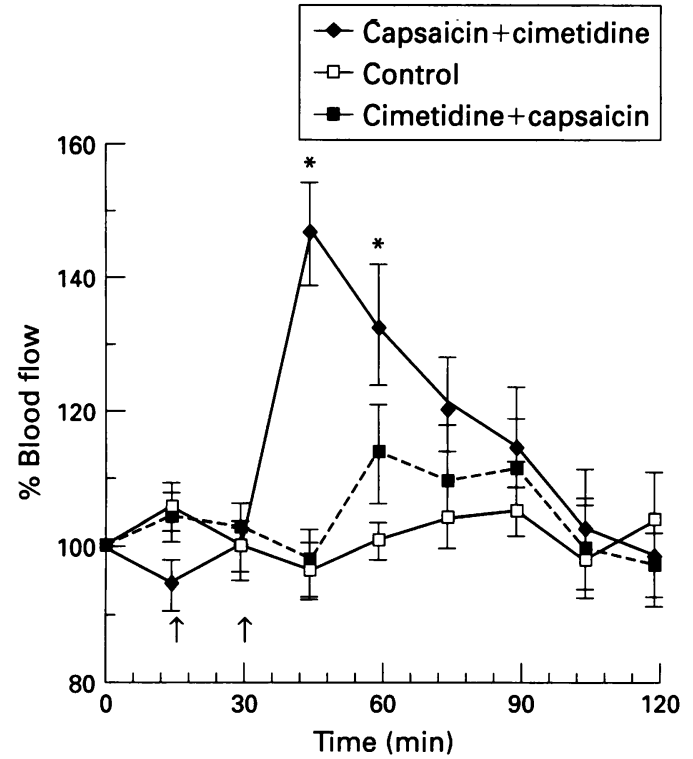

Dose response study of cimetidine

A dose response effect was clearly seen, increasing dose of cimetidine being associated with low gastric mucosal blood flow rates (Fig 4). Areas under the curve were (mean (SEM) units): $519.0(21.8), 773.6(42.4), 520.2$ (38.2), $455.5(41.7), 445.9(44.2)$, and 433.7 $(15 \cdot 0)$ for the control, capsaicin, $20 \mathrm{mg}$ cimetidine, $40 \mathrm{mg}$ cimetidine, $80 \mathrm{mg}$ cimetidine, and $160 \mathrm{mg}$ cimetidine groups respectively. The area under the curve was significantly greater for the capsaicin group compared with all other groups. However, for the different cimetidine doses only the $160 \mathrm{mg}$ group was significantly lower than control. The area under the curve was also significantly lower for the $160 \mathrm{mg}$ group compared with the $20 \mathrm{mg}$ group.

\section{GASTRIC ACID SECRETION}

Effect of capsaicin, cimetidine, and their combination

The total amounts of acid secreted after treatment in the solvent, capsaicin, cimetidine, capsaicin plus cimetidine, and cimetidine plus

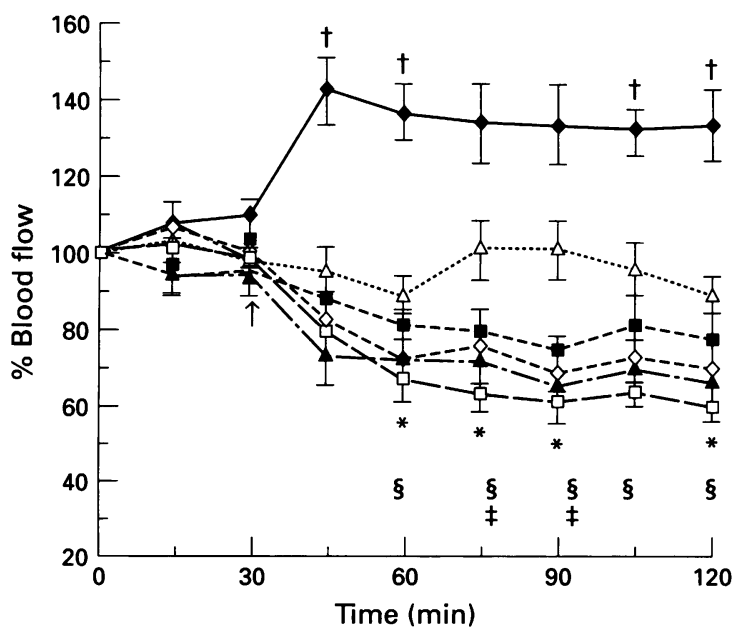

Capsaicin

Control

Cimetidine $(20 \mathrm{mg})$ Cimetidine $(40 \mathrm{mg})$ Cimetidine $(80 \mathrm{mg})$ Cimetidine $(160 \mathrm{mg})$

Figure 4: Effect of different doses of cimetidine on gastric mucosal blood flow ( $n=8$ per group). Data shown as mean (SEM). Time of exposure to drug arrowed. $p<0.05$ : $\dagger$ capsaicin $\mathrm{v}$ control, $\ddagger$ cimetidine $20 \mathrm{mg} \mathrm{v}$ control, ${ }^{\star}$ cimetidine $40 \mathrm{mg} \mathrm{v}$ control, Icimetidine $80 \mathrm{mg}$ and $160 \mathrm{mg} \mathrm{v}$ control. capsaicin groups (mean (SEM)) were: $39 \cdot 0$ $(10 \cdot 1) \mu \mathrm{mol}, 43.7(11.0) \mu \mathrm{mol}, 0.5(0.4) \mu \mathrm{mol}$ $(\mathrm{p}<0.05$ versus control, capsaicin, capsaicin plus cimetidine, and cimetidine plus capsaicin groups), $6.7(2.9) \mu \mathrm{mol}(\mathrm{p}<0.05$ versus control, capsaicin, and cimetidine groups), and $3.2(6.3) \mu \mathrm{mol}(\mathrm{p}<0.05$ versus control, capsaicin, and cimetidine groups).

\section{Dose response study of cimetidine}

Treatment with cimetidine at various doses rapidly increased gastric juice $\mathrm{pH}$. The total amounts of acid secreted in the 90 minutes after treatment in the control, capsaicin, cimetidine $20 \mathrm{mg}$, cimetidine $40 \mathrm{mg}$, cimetidine $80 \mathrm{mg}$, and cimetidine $160 \mathrm{mg}$ groups (mean (SEM)) were: $76.4(18.8) \mu \mathrm{mol}, 76.8$ $(22.4) \mu \mathrm{mol}, 30.3(21.1) \mu \mathrm{mol}(\mathrm{p}<0.05$ versus control, capsaicin, and cimetidine $40 \mathrm{mg}, 80$ $\mathrm{mg}$, and $160 \mathrm{mg}$ groups), 3.5 (1.9) $\mu \mathrm{mol}$ $(p<0.05$ versus control, capsaicin, and cimetidine $80 \mathrm{mg}$ and $160 \mathrm{mg}$ groups), $0 \mu \mathrm{mol}$ $(p<0.05$ versus control, capsaicin, cimetidine $20 \mathrm{mg}$ and $40 \mathrm{mg}$ groups $)$ and $0 \mu \mathrm{mol}(\mathrm{p}<0.05$ versus control, capsaicin, cimetidine $20 \mathrm{mg}$ and $40 \mathrm{mg}$ groups). A dose response effect was therefore evident.

\section{Discussion}

There are epidemiological data suggesting a beneficial role for chilli, which contains capsaicin, in human peptic ulcer disease. ${ }^{14} \mathrm{We}$ have previously shown a protective effect of capsaicin against aspirin induced gastric mucosal injury in human volunteers. ${ }^{15}$ Animal studies also suggested a role for capsaicin sensitive neurones in the repair of gastric mucosal injury. ${ }^{45}$ Capsaicin is therefore a potential therapeutic agent for peptic ulcer disease in humans. Its effect in the healing of experimental gastric ulcer and possible interaction with other ulcer healing drugs is thereby of interest.

Cimetidine is a histamine 2 receptor antagonist, which inhibits gastric acid output and is widely used for the treatment of peptic ulcer in humans. ${ }^{7}$ It is also known to accelerate the healing of experimental gastric ulcer. ${ }^{8} \mathrm{We}$ therefore chose to compare cimetidine with capsaicin in this respect. As expected cimetidine at a dose of $40 \mathrm{mg}$ daily did increase ulcer healing compared with control animals. Oral capsaicin at a dose of $5 \mathrm{mg}$ daily also improved ulcer healing. Unexpectedly, combination treatment using capsaicin and cimetidine, while still effective compared with the control group, was less efficacious than the use of capsaicin alone.

Capsaicin is known to increase gastric blood flow and this is thought to be one mechanism for its gastroprotective effect. ${ }^{1}$ In contrast, cimetidine has previously been shown to reduce gastric mucosal blood flow, ${ }^{16}$ a finding confirmed in this study. We therefore investigated the effect of combined treatment on gastric mucosal blood flow. To measure gastric acid secretion, the solution bathing the gastric chamber preparation has to be aspirated at 
regular intervals. To eliminate the possibility of the capsaicin and cimetidine solutions interacting physically during the 15 minutes in the gastric chamber, we gave the two solutions consecutively rather than simultaneously. Pilot studies suggested that the sequence of administration made a difference to the effect of combination treatment on mucosal blood flow. Application of cimetidine after hyperaemia had already been initiated with capsaicin did not have any significant effect on subsequent gastric mucosal blood flow. However, the use of cimetidine followed by capsaicin abolished the hyperaemic effect of the latter. Cimetidine can therefore prevent the hyperaemic effect of capsaicin but cannot reverse hyperaemia once it has occurred. The pharmacological basis of this interaction remains to be worked out.

Published works on the effect of capsaicin on gastric acid output are confusing. Basal acid output is not affected either by desensitisation or by intragastric capsaicin administration. ${ }^{17-20}$ However, pentagastrin stimulated gastric acid output was said to be increased, ${ }^{21}$ or reduced ${ }^{17}$ by intragastric capsaicin administration while capsaicin desensitisation either reduced $^{19}$ pentagastrin stimulated acid output, or had no effect. ${ }^{19}$ Differences in the experimental protocol, for example, use of anaesthesia, or the dosages of pentagastrin may have accounted for some of these differences. In contrast, calcitonin gene related peptide, which is released by capsaicin from sensory nerves and which is thought to be a mediator of capsaicin induced gastric hyperaemia and gastroprotection, has been shown by several groups to inhibit both basal and stimulated gastric acid secretion. ${ }^{22-24}$ It would seem that any effect of capsaicin on gastric acid output may not be relevant to its gastroprotective properties. As expected, application of capsaicin in our gastric chamber preparation had no effect on acid output but cimetidine use reduced gastric acid secretion in a dose related fashion. Addition of capsaicin to cimetidine did not affect the inhibiting effect of the latter or acid secretion. We postulate that the antagonistic effect on ulcer healing of cimetidine when combined with capsaicin is due to reduction of gastric blood flow by cimetidine.

Combined administration of cimetidine with epidermal growth factor, also an ulcer healing agent ${ }^{10}$ and stimulator of gastric mucosal blood flow, ${ }^{25}$ increased the healing of experimental gastric ulcer compared with administration of each substance alone. ${ }^{8}$ Other histamine 2 receptor antagonists do not have the same effect as cimetidine on gastric mucosal blood flow. Burimamide, for example increased gastric blood flow $^{26}$ while metiamide, ${ }^{26}$ ranitidine, ${ }^{27}$ and ebrotidine ${ }^{27}$ had no effect. It remains to be seen whether combination treatment using capsaicin plus epidermal growth factor or histamine 2 antagonists other than cimetidine will increase the rate of ulcer healing compared with single agent treatment.
This work was supported by Research Grant RP900309, National University of Singapore as well as GR $06085 \mathrm{H}$ generously donated by the Shaw Foundation. We would like to thank ously donated by the Shaw Foundation. We would
Associate Professor K C Lun for statistical advice.

1 Holzer P, Pabst MA, Lippe I Th, Peskar BM, Peskar BA, Livingston EH, et al. Afferent nerve-mediated protection against deep mucosal damage in the rat stomach. Gastroenterology 1990; 98: 838-48.

2 Uchida $M$, Yano $S$, Watanabe $K$. The role of capsaicin sensitive afferent nerves in protective effect of capsaicin sensitive afferent nerves in protective effect of capsaicin against absolute ethanol-induced

3 Holzer P, Pabst MA, Lippe I Th. Intragastric capsaicin protects against aspirin-induced lesion formation and bleeding in the rat gastric mucosa. Gastroenterology 1989; 96: 425-33.

4 Takeuchi K, Ueshima K, Ohuchi T, Okabe S. The role of capsaicin sensitive sensory neurones in healing of $\mathrm{HCl}-$ induced gastric mucosal lesion in rats. Gastroenterology 1994; 106: 1524-32.

5 Tramontana M, Renzi D, Calabro A, Panerai C, Milani S, Surrenti $\mathrm{C}$, et al. Influence of capsaicin-sensitive afferent fibers on acetic acid-induced chronic gastric ulcer in rats. fibers on acetic acid-induced chronic gast

6 Pabst MA, Schoninkle E, Holzer P. Ablation of capsaicin sensitive afferent nerves impairs defence but not rapid repair of rat gastric mucosa. Gut 1993; 34: 897-903

7 Blackwood WS, Maudgal DP, Pickard RG, Lawrence D, Northfield TC. Cimetidine in duodenal ulcer. Lancet 1976; ii: 174-6.

8 Olsen PS, Poulsen SS, Therkelsen K, Nexo E. Effect of sialoadenectomy and sythetic human urogastrone on healing of chronic gastric ulcer in rats. Gut 1986; 27: 1443-9.

9 Okabe S, Roth JLA, Pfeiffer CJ. A method for experimental penetrating gastric and duodenal ulcer in rats. Dig Dis penetrating gastric

10 Konturek SJ, Dembinski A, Warzecha Z, Bielanski W, Brzozowski T, Drozdowicz D. Epidermal growth factor in the gastro-protective and ulcer healing actions of colloidal bismuth subcitrate in rats. Gut 1988; 29: 894-902.

11 Mersereau WA, Hinchey EJ. Effect of gastric acidity on gastric ulceration induced by hemorrhage in the rat, utilising a gastric chamber technique. Gastroenterology 1973; 64: $1130-5$.

12 SAS Institute Inc. SAS user's guide: Statistics. Version 5. North Carolina, USA: SAS Institute Inc, 1985: 651.

13 Konturek SJ, Brzozowski T, Majka J, Szlachcic A, Bielanski $\mathrm{W}$, Stachura J, et al. Fibroblast growth factor in gastroprotection and ulcer healing: interaction with sucralfate. protection and ulcer

14 Kang JY, Yeoh KG, Chia HP, Lee HP, Chia YW, Guan R, et al. Chilli-protective factor against peptic ulcer? Dig Dis Sci 1995; 40: 576-9.

15 Yeoh KG, Kang JY, Yap I, Guan R, Tan CC, Wee A, et al. Chilli protects against aspirin-induced gastroduodenal mucosal injury in humans. Dig Dis Sci 1995; 40: 580-3.

16 Cheung LY, Sonnenschein. Effects of histamine and cimetidine on gastric blood flow and intramural $\mathrm{pH}$ in dogs [Abstract]. Gastroenterology 1981; 80: 1123 .

17 Lippe ITh, Pabst MA, Holzer P. Intragastric capsaicin enhances rat gastric acid elimination and mucosal blood enhances rat gastric acid elimination and mucosal blood
flow by afferent nerve stimulation. Br f Pharmacol 1989; 96: $91-100$.

18 Dugani AM, Glavin GB. Capsaicin effects on stress pathology and gastric acid secretion in rats. Life Sci 1985; 39; $1531-8$.

19 Alfoldi P, Obal F Jr, Toth E, Hideg J. Capsaicin pre-treatment reduces the gastric acid secretion elicited by histamine but does not affect the responses to carbachol and pentagastrin. Eur $\mathcal{F}$ Pharmacol 1986; 123: 321-7.

20 Kang JY, Teng CH, Wee A, Chen FC. The effect of capsaicin and chilli on ethanol-induced gastric mucosal injury in the rat. Gut 1995; 36: 664-9.

21 Limlomwongse L, Chaitachawong C, Tongyai S. Effect of capsaicin on gastric acid secretion and mucosal blood flow capsaicin on gastric acid secretion and

22 Holzer P, Peskar BM, Peskar BA, Amann R. Release of calcitonin gene-related peptide induced by capsaicin in the vascularly perfused stomach. Neurosci Lett 1990; 108: 195-200.

23 Lenz HJ, Mortrud MT, River JE, Brown MR. Calcitonin gene-related peptide inhibits basal, pentagastrin, histamine, and bethanecol stimulated gastric acid secretion. Gut 1985; 26: 550-5.

24 Tache $Y$, Pappas T, lauffenberger $M$, Goto $Y$, Walsh JH, Debas H. Calcitonin gene-related peptide: potent peripheral inhibitor of gastric acid secretion in rats and dogs. Gastroenterology 1984; 87: 344-9.

25 Hui WM, Chan BW, Kung AWC, Cho CH, Luk CT, Lam SK. Effect of epidermal growth factor on gastric blood flow in rats; possible role in mucosal protection. Gastroenterology 1993; 104: 1605-10.

26 Main IHM, Whittle BJR. A study of the vascular and acid secretory responses of the rat gastric mucosa to histamine. secretory responses of the rat

27 Brzozowski T, Majka, J, Konturek SJ. Gastroprotective and ulcer healing activities of a new $\mathrm{H} 2$ receptor antagonist: ebrotidine. Digestion 1992; 51: 27-36. 